\title{
Parents' attitude towards the importance of sex education for their children
}

\author{
Safaa Rashad Mahmoud ${ }^{1}$, Nabila Taha Ahmed ${ }^{2}$, Hosnia Shehata Mohammed ${ }^{3}$, Faransa Ali Ahmed ${ }^{4} \&$ \\ Nadia Hussein Ahmed \\ ${ }^{1 .}$ Assistant Professor of Community Health Nursing, Faculty of Nursing, Assiut University, Egypt. \\ 2. Professor of Obstetrics \& Gynecological Health Nursing, Faculty of Nursing, Assiut University, Egypt. \\ 3. Assistant Professor of Psychiatric Nursing, Faculty of Nursing, Assiut University, Egypt. \\ 4. Assistant Professor of Pediatric Nursing, Faculty of Nursing, Assiut University, Egypt. \\ 5. Assistant Professor of Obstetrics \& Gynecological Nursing, Faculty of Nursing, Assiut University, Egypt.
}

\begin{abstract}
:
Background: Numerous parents confront challenges to reply to their children' sexual issues. These issues are usually unexpected, but responding in a positive and proportional manner to them is the most difficult aspect of parenting. Aim: to explore the parents' attitude towards sex-education for their children. Design: Descriptive design was used in this study. Convenient sample of 545 parents were recruited for this study. Setting: Assiut University employees' work place. Tool: A structured interview questionnaire which includes 2 parts; 1 - Personal data for both parents such as age, education, residence and number of their children. 2- Parents' attitude scale which was developed by the researchers to investigate parent' attitude toward sex education, it includes 29 statements with response of Yes/No. Results: There was positive attitude among more than three-quarters of participated parents, $58.5 \%$ of them reported that both mother and father are responsible for sex education. There are statistically significant relation between parents' talk about sex education, parents' sex, and mother education $(\mathrm{P}=0.000$, and 0.001$)$. Conclusion \& Recommendations: The majority of studied parents have positive attitudes towards sex-education to their children. Sex and age of parents, mother' education, and residency are factors which influences their attitudes. Conducting more research on trends towards sex education in a larger sample, and arrange obligatory training program and workshops for parents of 10 years or more children on their sex education.
\end{abstract}

\section{Keywords: Attitude, Children, Parent \& Sex education}

\section{Introduction}

Sex education is a lifelong process of knowledge' acquisition and formation of attitudes, beliefs and values concerning sex toward establishing a strong base for sexual health. Parents play a critical role in sex education to their children, supporting them in recognizing their sexuality developmental phases, and their attitude to their opposite sex. (Ariadni et al., 2017 \& Obiunu, 2014).

Sex health education takes place every day at homes, schools, religious institutions, and via mass-media. Experts in child rearing agree that sex education should begin at a young age and be handled in an open and naturalistic manner (Nghipondoka- Lukolo \& Charles, 2016). The age at which sex education should begin has also been broadly discussed. Many scholars now suggest that it should be taught in elementary school level (Aku Baku et al., 2017). Adolescents who have early conversations with their parents about sexual wellbeing and safe sex tend to engage in less risky sexual activity than those whose parents do not. In some countries such as Egypt, Sex health education is necessary for the beginning of the marital life (Bostani Khalesi et al., 2017).
Sex health is one of life's most essential elements. However, due to cultural and political sensitivities, they are often overlooked in public policy debates. In Egypt, conventional devout and family values, outlined to protect youth, can limit sex health education for children. Egyptians commonly believe that youth should not be educated about sex health issues till they are married. This viewpoint is supported by traditional and long-standing sex restrictions that must be examined in the context of health protection (WHO, 2018 \& Roudi-Fahimi, 2011).

Numerous parents struggle to respond to their children's sexual concerns. These problems are usually unexpected, but responding in a positive and proportional manner to them is the most difficult aspect of parenting. So, by recognizing sexual questions that children often pose, and by providing adequate education to parents, responses to children's curious questions can be tailored. (Ghorbani et al., 2015).

Children who have parents who share their behaviors, values, and beliefs are more likely to follow the same value system as their parents. As children enter puberty, when significant lifestyle choices must be made, this system of beliefs becomes increasingly 
relevant (UNICEF \& Ministry of Education, 2016). If open lines of communication on sexual issues have not been well developed during adolescence, it is often difficult for parents to have relaxed discussions about sexual topics with their teenage children. As a result, deficiency or absence of sexual education can lead to health and social risks such as sexually transmitted diseases (STDs) and unintended pregnancies (Campbell, 2017).

School nurses are community health nurses that specialize in working with the school- aged children to enhance their health and well-being and are thus in a unique position to promote the sexual health of children and adolescent. These nurses play an important role in sexual health by developing schoolbased health services, and providing sex and relationships education (Beech \& Sayer, 2018).

\section{Significance of the Study}

Despite widespread awareness of the importance of youth sexual and reproductive health (SRH) as an important component of overall health and wellbeing, Egypt's research in this area is limited. More than $40 \%$ of the country's population is made up of young people aged 10 to 29 (Population Council 2016). Despite Egypt's increasing population of teenagers and youth and their possible exposure to high-risk behaviors, little is known about their sexual and reproductive health awareness and practices.

Many parents often discourage the discussion of sex or sexually related matters; this has made adolescents to discuss sex-related problems with their peers rather than their parents. Although parents and schools both have a role to play in sex education, it has been found that parents infrequently speak to their children in a timely and comprehensive manner, and schools are constrained in what they can teach (Hildie et al., 2019, Flores \& Barroso, 2017, Haberland \& Rogow, 2015).

Good parent-adolescent communication about sexual and reproductive health (SRH) is critical in order to reduce risky sexual activity among teenagers (Tayo \& Olawuyi, 2016). In Egypt, such communication is restricted (Hassan, 2013). This study therefore intends to critically investigate the attitude of parents towards sex education for their children.

Aim of the study:

To explore the parents' attitude towards sex-education for their children.

\section{Research Question:}

What are parents' attitudes toward sex education of their children?

What are the relationship between parents' attitudes toward sex education and their personal characteristics?

\section{Subjects \& Methods \\ Study Design:}

Descriptive design was used in the current study.

Setting:

The study was carried out at all faculties of Assiut University, Assiut University Hospitals, and University Student's Dormitory.

Study sample: A convenient sample of all employed parents working in previous mentioned settings. They composed 545 parents who have at least one child of 10 years or more.

Tool of the study:

An interview questionnaire was adapted from much the same studies conducted on sex education and modified to meet our goal of ensuring the data's content validity (Fentahun et al., 2012, Kashik, 2012, Nyarko et al., 2014, Netshisaulu et al., 2015, \& Robinson et al., 2017). It composed of two parts: First part; contains personal data as age, education, residence, number of children \& their sex, if the parent talk about sex with their children, their opinion about the suitable age for sex education, and who is responsible for sex education.

Second part; Parents' attitude scale, which was developed by the researchers and composed of 29 statements. It designed to investigate the parents' attitudes toward sex education, their responds by yes or no.

(Sex education concepts in this questionnaire refer to the etiquette of seeking permission before entering upon parents, personal hygiene of the genitals, wet dreams, hair growth under axilla and pubic area, breast prominence, menstruation, and masturbation, etc.....).

Scoring system:

The scale composed of 29 statements; 23 of them express positive statements, each response is classified to yes $=1 \&$ no $=0$. And 6 negative (reversed) statements (no. 2, 3, 4, 19, 20, \& 25), each response is classified to yes $=0 \&$ no $=1$. Total score of scale was 29 , if total score of parents had $18=60 \%$ and more it means satisfactory (positive) attitudes.

Content Validity \& Reliability of the tool:

Validity of the tool was done, before actual study was started through a jury panel of five experts in the field of community, maternity \& psychiatric nursing.

Reliability was measured using Cronbach's Alpha test on $10 \%$ of cases it was 0.789

Administrative design:

- An official permission was granted through the faculty of nursing to the director general of manpower administration to get the number of married employees

- Directors of each setting were informed. 


\section{Ethical considerations:}

Research proposal was approved from ethical committee in the faculty of nursing. Explain the nature \& purpose of the study to the participated employees. There was no harm for the employees from the study which followed common ethical principles of research. Anonymity and confidentiality were assured. The participants had the option to refuse participation or withdraw from the study at any time.

Pilot study:

Pilot study was done by using well designed and revised tool to test its clarity \& feasibility on $10 \%$ of the study participants and before the actual study carried out. After conducting a pilot study no modification was required so the sample of pilot study was included in the actual study sample.

\section{Field work:}

Parents who participated in the study were informed that completion of the study will be voluntary. In the work break time of employees, the investigators met them individually or in a small group according to the working condition in their offices and provide an explanation about the nature and importance of the study. Then distributed the study tool to gather the data and answer any question arising from participants. After that the investigators collected the study tool from participants and thanks them for their time expended in study participation. Then reviewed the collected tool to make sure of its completeness. The data was collected three days a week, from 7 to 8 participants a day from first of October 2018 to the end of March 2019 (6 months). Duration of each interview was ranged from 20 to 25 minutes.

Statistical analysis:

The Statistical Package for Social Sciences (SPSS) version 26 for Windows was used to analyze the data. Data were presented in the form of frequencies, percentages, means \pm SD and Chi-square test. Test of significance were considered as a follows: No significant (NS) $\mathrm{P}>0.05$, significant $\mathrm{P}<0.05$ and highly significance $\mathrm{P}<0.01$.

\section{Results:}

Five hundred forty-five parents participated in the current study, $67.2 \%$ of them were the mother, regarding father's

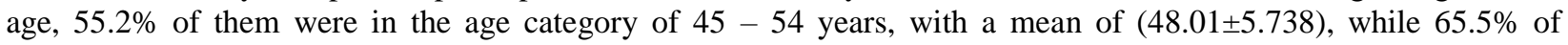
mothers were in the age category of $35-44$ years, with a mean of $(42.78 \pm 5.273) .71 .6 \%$ of parents live in urban area. In addition, $58.2 \%$ and $52.1 \%$ of father and mother had university education respectively. $36.7 \%$ of parents have two boys, and $35.6 \%$ of them have three girls or more.

Table (1): Distribution of the parents according to their opinion about suitable age, who is responsible, and if they talk with children about sex education

\begin{tabular}{|l|c|c|}
\hline \multicolumn{1}{|c|}{ Variable } & $\begin{array}{c}\text { No. } \\
(\mathbf{n . = 5 4 5})\end{array}$ & \% \\
\hline Suitable age for sex education & & 4.0 \\
\hline Don't know & 22 & 10.8 \\
\hline 3 year $-<$ 9years & 59 & 65.7 \\
\hline $9-<16$ years & 358 & 19.4 \\
\hline$\geq 16$ years & 106 & \\
\hline Who is responsible for sex education & & 2.0 \\
\hline Father & 11 & 24.8 \\
\hline Mother & 135 & 58.5 \\
\hline Both father and mother & 319 & 14.7 \\
\hline School & 80 & \\
\hline Talk with children about sex education & & 37.8 \\
\hline Yes & 206 & 62.2 \\
\hline No & 339 & \\
\hline
\end{tabular}


Table (2): Distribution of parents' attitude towards the importance of sex education for their children $($ n. $=545)$

\begin{tabular}{|c|c|c|c|c|}
\hline \multirow{2}{*}{ Statements } & \multicolumn{2}{|c|}{ Yes } & \multicolumn{2}{|c|}{ No } \\
\hline & n. & $\%$ & n. & $\%$ \\
\hline 1. Sex education becomes necessary. & 450 & 82.6 & 95 & 17.4 \\
\hline 2. I blush to talk about sex culture. & 236 & 43.3 & 309 & 56.7 \\
\hline 3. Refuse to talk about sexual culture. & 376 & 69.0 & 169 & 31.0 \\
\hline 4. I do not recognize the sex education of children. & 390 & 71.6 & 155 & 28.4 \\
\hline 5. I want to educate my children about sex. & 431 & 79.1 & 114 & 20.9 \\
\hline 6. Sex education is part of the general human culture & 450 & 82.6 & 95 & 17.4 \\
\hline 7. Sex Education for children is useful. & 446 & 81.8 & 99 & 18.2 \\
\hline 8. Sex education from an early stage reduces sex problems in the future. & 458 & 84.0 & 87 & 16.0 \\
\hline 9. We should educate our children about a different sex culture from the Western culture. & 484 & 88.8 & 61 & 11.2 \\
\hline 10. The questions of the sex must be answered in accordance with their understanding. & 480 & 88.1 & 65 & 11.9 \\
\hline 11. The father directs the boys and the mother to direct the girls sexually. & 449 & 82.4 & 96 & 17.6 \\
\hline 12. We should talk with our male children about the wet dreams. & 171 & 31.4 & 374 & 68.6 \\
\hline $\begin{array}{l}\text { 13. We should talk with our children about the growth of pubic and axilla hair and how } \\
\text { to get rid of them. }\end{array}$ & 279 & 51.2 & 266 & 48.8 \\
\hline $\begin{array}{l}\text { 14. We should talk with our teenage daughters about the growth and appearance of the } \\
\text { breasts and how to deal with this growth. }\end{array}$ & 247 & 45.3 & 298 & 54.7 \\
\hline $\begin{array}{l}\text { 15. We should talk with our teenage daughters about menstruation, care and personal } \\
\text { hygiene during it. }\end{array}$ & 269 & 49.4 & 276 & 50.6 \\
\hline $\begin{array}{l}\text { 16. We should talk with our children about separation between male and female children } \\
\text { when bathing and sleeping. }\end{array}$ & 384 & 70.5 & 161 & 29.5 \\
\hline 17. We should talk with our children about genital hygiene. & 385 & 70.6 & 160 & 29.4 \\
\hline 18. We should talk with our children about the proper dress that not attract for lust. & 385 & 70.6 & 160 & 29.4 \\
\hline 19. It is better to discuss sexual issues with their schoolmates. & 434 & 79.6 & 111 & 20.4 \\
\hline 20. Discussion about sex makes children less shy. & 320 & 58.7 & 225 & 41.3 \\
\hline 21. Talking to children about sexual concepts protect them from misinformation. & 418 & 76.7 & 127 & 23.3 \\
\hline $\begin{array}{l}\text { 22. Talking about sexual concepts encourage children to buy scientific books on this } \\
\text { subject. }\end{array}$ & 336 & 61.7 & 209 & 38.3 \\
\hline 23. The child should not sleep with his parents after his first year. & 408 & 74.9 & 137 & 25.1 \\
\hline $\begin{array}{l}\text { 24. The child's questions should be answered in a scientific manner appropriate to their } \\
\text { age. }\end{array}$ & 467 & 85.7 & 78 & 14.3 \\
\hline 25. Children should be punished when they plays in their genital organs. & 300 & 55.0 & 245 & 45.0 \\
\hline 26. Parents should understand sexual issues before explaining to their children. & 483 & 88.6 & 62 & 11.4 \\
\hline 27. Attention must be paid to the youth and direct those to useful objects. & 515 & 94.5 & 30 & 5.5 \\
\hline 28. Children should get used to the permission before entering parents during bedtime. & 534 & 98.0 & 11 & 2.0 \\
\hline $\begin{array}{l}\text { 29. Erotic movies, channels or websites or magazines and books must be avoided for } \\
\text { children. }\end{array}$ & 533 & 97.8 & 12 & 2.2 \\
\hline
\end{tabular}




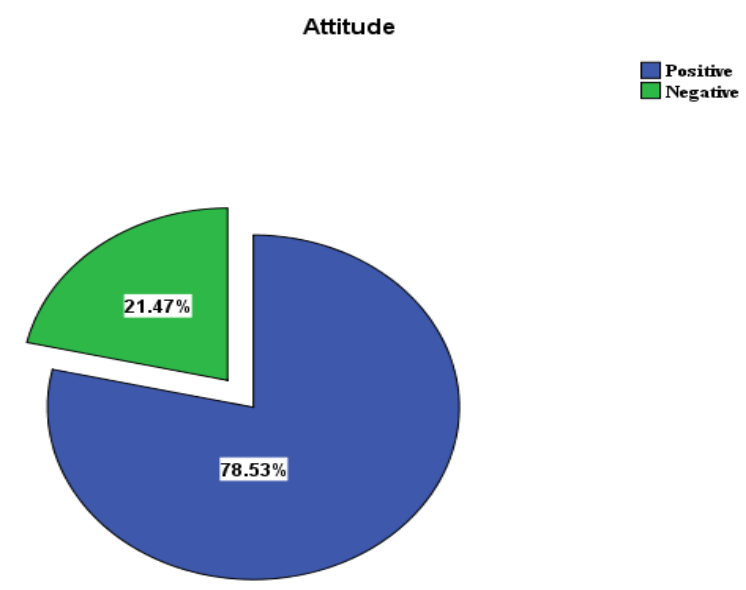

Figure (1): Parents' total attitude score towards the importance of sex education for their children

Table (3): Relationship between parents' total attitude score towards the importance of sex education and their personal characteristics

\begin{tabular}{|c|c|c|c|c|c|}
\hline \multirow{2}{*}{ Variable } & \multicolumn{2}{|c|}{ Negative } & \multicolumn{2}{|c|}{ Positive } & \multirow{2}{*}{$P$ - value } \\
\hline & No. & $\%$ & No. & $\%$ & \\
\hline \multicolumn{5}{|l|}{ Parents } & \multirow[t]{3}{*}{$0.000 * *$} \\
\hline Father & 78 & 14.3 & 101 & 18.5 & \\
\hline Mother & 39 & 7.2 & 327 & 60.0 & \\
\hline \multicolumn{5}{|l|}{ Father's age } & \multirow[t]{4}{*}{$0.000 * *$} \\
\hline $35-44$ & 41 & 7.5 & 112 & 20.6 & \\
\hline $45-54$ & 72 & 13.2 & 229 & 42.0 & \\
\hline$\geq 55$ & 4 & 0.7 & 87 & 16.0 & \\
\hline \multicolumn{5}{|l|}{ Mother's age } & \multirow[t]{4}{*}{$0.000^{* *}$} \\
\hline $35-44$ & 98 & 18.0 & 259 & 47.5 & \\
\hline $45-54$ & 19 & 3.5 & 146 & 26.8 & \\
\hline$\geq 55$ & 0 & 0.0 & 23 & 4.2 & \\
\hline \multicolumn{5}{|l|}{ Residence } & \multirow[t]{3}{*}{$0.000 * *$} \\
\hline Rural & 51 & 9.4 & 104 & 19.1 & \\
\hline Urban & 66 & 12.1 & 324 & 59.4 & \\
\hline \multicolumn{5}{|l|}{ Father's education } & \multirow[t]{5}{*}{0.834} \\
\hline Diploma & 28 & 5.1 & 89 & 16.3 & \\
\hline Technical institute & 17 & 3.1 & 74 & 13.6 & \\
\hline University & 68 & 12.5 & 249 & 45.7 & \\
\hline post graduated & 4 & 0.7 & 16 & 2.9 & \\
\hline \multicolumn{5}{|l|}{ Mother's education } & \multirow[t]{5}{*}{$0.000 * *$} \\
\hline Diploma & 50 & 9.2 & 96 & 17.6 & \\
\hline Technical institute & 7 & 1.3 & 81 & 14.9 & \\
\hline University & 57 & 10.5 & 227 & 41.7 & \\
\hline Post graduated & 3 & 0.6 & 24 & 4.4 & \\
\hline \multicolumn{5}{|l|}{ Number of boys } & \multirow[t]{5}{*}{0.645} \\
\hline None & 16 & 2.9 & 48 & 8.8 & \\
\hline 1 & 46 & 8.4 & 152 & 27.9 & \\
\hline 2 & 40 & 7.3 & 160 & 29.4 & \\
\hline$\geq 3$ & 15 & 2.8 & 68 & 12.5 & \\
\hline
\end{tabular}




\begin{tabular}{|l|c|c|c|c|c|}
\hline \multirow{2}{*}{ Variable } & \multicolumn{2}{c|}{ Negative } & \multicolumn{2}{c|}{ Positive } & \multirow{2}{*}{ P - value } \\
\cline { 2 - 5 } & No. & \% & No. & \% & \multirow{2}{*}{$0.001^{* *}$} \\
\hline Number of girls & & & & & \\
\cline { 1 - 5 } None & 5 & 0.9 & 58 & 10.6 & \\
\hline 1 & 53 & 9.7 & 141 & $\mathbf{2 5 . 9}$ & \\
\hline 2 & 42 & 7.7 & 125 & 22.9 & \\
\hline$\geq 3$ & 17 & 3.1 & 104 & 19.1 & \\
\hline
\end{tabular}

** P. Value is highly significant at $P<0.01$

Table (4): Relationship between parents' talk about sex education and their personal characteristics

\begin{tabular}{|c|c|c|c|c|c|}
\hline \multirow{2}{*}{ Variable } & \multicolumn{2}{|c|}{ Talk } & \multicolumn{2}{|c|}{ Didn't talk } & \multirow{2}{*}{$\mathrm{P}$ - value } \\
\hline & No. & $\%$ & No. & $\%$ & \\
\hline \multicolumn{5}{|l|}{ Parents } & \multirow{3}{*}{$0.000 * *$} \\
\hline Father & 45 & 8.3 & 134 & 24.6 & \\
\hline Mother & 161 & 29.5 & 205 & 37.6 & \\
\hline \multicolumn{5}{|l|}{ Father's age } & \multirow{4}{*}{0.828} \\
\hline $35-44$ & 55 & 10.1 & 98 & 18.0 & \\
\hline $45-54$ & 117 & 21.5 & 184 & 33.8 & \\
\hline More than or equal to 55 & 34 & 6.2 & 57 & 10.5 & \\
\hline \multicolumn{5}{|l|}{ Mother's age } & \multirow{4}{*}{0.230} \\
\hline $35-44$ & 128 & 23.5 & 229 & 42.0 & \\
\hline $45-54$ & 66 & 12.1 & 99 & 18.2 & \\
\hline More than or equal to 55 & 12 & 2.2 & 11 & 2.0 & \\
\hline \multicolumn{5}{|l|}{ Residence } & \multirow{3}{*}{0.093} \\
\hline Rural & 50 & 9.2 & 105 & 19.3 & \\
\hline Urban & 156 & 28.6 & 234 & 42.9 & \\
\hline \multicolumn{5}{|l|}{ Father's education } & \multirow{5}{*}{0.422} \\
\hline Diploma & 52 & 9.5 & 65 & 11.9 & \\
\hline technical institute & 33 & 6.1 & 58 & 10.6 & \\
\hline University & 114 & 20.9 & 203 & 37.2 & \\
\hline post graduated & 7 & 1.3 & 13 & 2.4 & \\
\hline \multicolumn{5}{|l|}{ Mother's education } & \multirow{5}{*}{$0.001 * *$} \\
\hline Diploma & 51 & 9.4 & 95 & 17.4 & \\
\hline technical institute & 48 & 8.8 & 40 & 7.3 & \\
\hline University & 102 & 18.7 & 182 & 33.4 & \\
\hline post graduated & 5 & 0.9 & 22 & 4.0 & \\
\hline \multicolumn{5}{|l|}{ Number of boys } & \multirow{5}{*}{0.064} \\
\hline None & 18 & 3.3 & 46 & 8.4 & \\
\hline 1 & 67 & 12.3 & 131 & 24.0 & \\
\hline 2 & 88 & 16.1 & 112 & 20.6 & \\
\hline$\geq 3$ & 33 & 6.1 & 50 & 9.2 & \\
\hline \multicolumn{5}{|l|}{ Number of girls } & \multirow{5}{*}{0.266} \\
\hline None & 21 & 3.9 & 42 & 7.7 & \\
\hline 1 & 84 & 15.4 & 110 & 20.2 & \\
\hline 2 & 59 & 10.8 & 108 & 19.8 & \\
\hline$\geq 3$ & 42 & 7.7 & 79 & 14.5 & \\
\hline
\end{tabular}


Table (5): Relationship between parents' total attitude score, the suitable age, responsibility, and talking about sex education

\begin{tabular}{|c|c|c|c|c|c|}
\hline \multirow{2}{*}{ Variable } & \multicolumn{2}{|c|}{ Negative } & \multicolumn{2}{|c|}{ Positive } & \multirow{2}{*}{$P$ - value } \\
\hline & No. & $\%$ & No. & $\%$ & \\
\hline \multicolumn{5}{|l|}{ Suitable age of sex education. } & \multirow{5}{*}{$0.000 * *$} \\
\hline Don't know & 11 & 2.0 & 11 & 2.0 & \\
\hline $1->9$ & 9 & 1.7 & 50 & 9.2 & \\
\hline $9->16$ & 62 & 11.4 & 296 & 54.3 & \\
\hline 16 and more & 35 & 6.4 & 71 & 19.4 & \\
\hline \multicolumn{5}{|c|}{ Who responsible about sex education } & \multirow{5}{*}{$0.000 * *$} \\
\hline father & 0 & 0.0 & 11 & 2.0 & \\
\hline mother & 28 & 5.1 & 107 & 19.6 & \\
\hline both mother and father & 42 & 7.7 & 277 & 50.8 & \\
\hline school & 47 & 8.6 & 33 & 6.1 & \\
\hline \multicolumn{5}{|l|}{ Talking about sex education } & \\
\hline Yes & 11 & 2.0 & 195 & 35.8 & \multirow[b]{2}{*}{$0.000 * *$} \\
\hline No & 106 & 19.4 & 233 & 42.8 & \\
\hline
\end{tabular}

$* * P$. Value is highly significant at $P<0.01$

Table (1): Illustrates that $65.7 \%$ of participated parents reported that age $(9->16$ years old) is more suitable age for sex education. Although $58.5 \%$ of parent reported that both mother and father are responsible, $62.2 \%$ of them didn't talk with their children about sex education.

Table (2): Represents the parents' attitude towards the importance of sex education for their children. It was found that the participated parents were agreeing for almost all positive statements of the questionnaire, which include; sex education becomes necessary $(82.6 \%)$, sex education from an early stage reduces sex problems in the future $(84 \%)$, parents should understand sexual issues before explaining to their children $(88.6 \%)$, erotic movies, channels or websites or magazines and books must be avoided for children (97.8\%). Also, there some negative statements which agreed by the participated parents such as; I do not recognize the sex education of children $(71.6 \%)$, it is better to discuss sexual issues with their schoolmates (79.6\%), and children should be punished when they plays in their genital organs $(55 \%)$.

Figure (1): Illustrates that there was positive attitude among $78.53 \%$ of the participated parents

Table (3): Clarifies that there was statistically significant relation between parents' attitude and their personal characteristics for all items regarding parental sex (mother), age of father (category of $45-$ 54 years) and mother (category of $35-44$ years), residence (urban). Moreover for mother's education (university education), $(\mathrm{P}=0.000)$, there was also statistically significant relation between parents' attitude and the number of their girls children $(\mathrm{P}=$ $0.001)$.
Table (4): Demonstrated that there are statistically significant relation between parents' talk about sex education and sex, and mother's education $(\mathrm{P}=0.000$, and 0.001) respectively. While there is no statistically significant relation regarding age of father and mother, residence, father's education, number of boys or girls.

Table (5): Represents that $54.3 \%$ of the participated parents who had positive attitude reported that the age from $9->16$ is suitable for sex education, and $50.8 \%$ of them mentioned that both mother and father are responsible about sex education for their children. The relation was statistically significant $(\mathrm{P}=0.000)$. It was observed that $42.8 \%$ of the participated parents who had positive attitude didn't talk with their children about sex education. The relation was statistically significant $(\mathrm{P}=0.000)$.

\section{Discussion}

Sex education is a subject on which most parents remain silent. Parents, especially mothers, have a critical role in providing sex education to their children in order to uphold them understand their sex developmental phases and attitudes toward their opposite sex (Ariadni et al., 2017).

The aim of the current study was to investigate the parent's attitude towards the importance of sexeducation for their children

The present study illustrated that there was positive attitude among more than three-quarters of the participated parents. These positive attitudes may be the result of [the growing knowledge of both fathers and mothers that both genders combine in schools, universities and clubs. Thus, children must learn the basics of sex education to be able to deal with gender 
diversity / others or perhaps they formed a desire to have a relationship with their children based on trust, frankness and affection, because they learned this lesson from their previous positive or negative experiences with their parents. At the end, the child must receive information from a reliable source such as parents, because their information will be trustworthy.

This result is harmonious with the study of Adogu \& Nwafulume, 2015 who evaluate the knowledge, attitude and willingness to teach sexual education among teachers in Nigeria. They found that many of male and female teachers have shown positive attitudes toward the subject of sex education for children.

The current study represented the parents' attitude towards the importance of sex education, the majority of them were agreeing for almost all positive statements of the questionnaire, such as sex education becomes necessary and useful, sex education is part of the general human culture, parents should understand sexual issues before explaining to their children, , also that sex-related questions must be answered in accordance with their understanding and in a scientific manner that is appropriate to their age. These results could be explained by observing and watching what is happening in the local, Arab and global environment in terms of changes in behaviors, customs, traditions, and even values. Parents are nowadays aware that they must be the main source of sexual knowledge in order to avoid negative influences from other unreliable sources.

The present findings were supported by (Ariadni et al., 2017) who investigate the viewpoints of parents having children with intellectual disability for providing sex education, both parents believe that sex education is necessary for children. Also these findings are in line to what Gurol et al., 2014 explains in their study, where all mothers, concur that sex education is important.

The current results were in consistent Jankovi etal., 2013, who assess parents' attitudes on sexual education, Their findings revealed that parents understand and support their children's need for a broad range of sex education knowledge. They also promote age-appropriate education; sex education is the responsibility of both the mother and the father.

The research of Vashistha, 2012 regarding attitudes toward sex-education as viewed by parents and teachers supports our finding as he found that the majority of parents supported sex-education for adolescents and had a positive behavior toward it; they believe that primary sex-education for adolescents should begin at home

The current results were in agreement with Katz \& Ponce, 2009 study about educational intervention regarding sex for parents and counselors in developing countries, they reported that it is essential to use vocabulary that their children will understand while providing sex education

Millner et al., 2015 who investigated the parents' attitude regarding sex education for their children in Alabama, their participants reported that sex education for children is very important,

Actually, parents and caregivers should serve as primary sex educators for their children. (Breuner $\&$ Mattson, 2016). The present study shows that greater than half of the participated parents reported that both mothers and fathers are responsible for sex education, while one-quarter of them mentioned the mother as a responsible for sex education

This finding is harmonious with findings from research in the United States, in which mothers are often cited as the primary sex educators at home, and mothers are consistently noted as being more included in involving their children in sex discussions. In addition, mothers were found to be more at ease addressing sex than fathers (Jo et al., 2013, Lee \& Kweon (2013), Flores \& Barroso (2017).

The study results of Shin et al., 2019 support present study finding, they found that most parents agreed that parents should be the first teachers and the ones primarily responsible for sex education for young children.

The findings are also in accordance with Nyarko et al., 2014 who studied parent's viewpoint of sex education at Ghana and found that half of fathers and more than a third of mothers agree that both parents should be responsible for their children's sex education

The current study clarified that there were statistically significant relation between parents' attitude and their personal characteristics for all items regarding sex, age of father and mother, residence, and for mother's education. The relation between parents' attitude and educational level can be attributed to the fact that acquiring more scientific and cultural knowledge may help parents be aware of what is presented in the social, academic and media institutions. This intellectual and cultural knowledge of well-educated parents is reflected in their attitudes and methods of dealing with their children. As regards sex, this could be due to the fact that mothers are closer to their children than fathers and have the responsibility to raise them and help them grow mentally, physically and psychologically as well as sexually.

These results are in agreement with Shin et al., 2019 who investigate sexual knowledge, attitudes, and perceptions among elementary school parents; they found that parental gender and education were strongly related to their positive attitudes 
The present study shows that although more than a third of the participated parents who had positive attitude, they didn't talk with their children about sex education. This finding can be explained as there are many misconceptions that remain until now as a result of wrong family upbringing. Despite technological developments, parents are still very shy when it comes to a frank and scientific talk about sex with their children. Parents do not give willingly any information or open any discussions regarding sexual matters. They rarely answer their children's sexual questions, and in many cases this rare given answer are ambiguous and unclear due to the parents' lack of proper scientific facts or scientific concepts or terms related to sexual matters, or because of the parents' embarrassment in commenting on their children's questions.

The finding is consistent with Lukolo \& Dyk, 2015 who evaluate the involvement of parents in their children's sexual education in Namibia, they found that most participated parents in their study reported that they never talked with their children about sex. Also this finding was concurred with Nyarko et al., 2014, their results demonstrated that more than half of fathers and more than one-third of mothers have never discussed sex with their children.

As well, the results of the current study were in consistent with an exploratory study that is done by Orgocka, 2010 regarding perceptions of mothers and their daughters about sex education. Findings indicated that communication was barred by mothers' embarrassment and lack of skills to talk about sex with their children.

Furthermore, a study conducted by Shetty et al, 2010, supported the current results, which revealed that mothers were uncomfortable regarding sex educating their daughters; they prefer that girls obtain knowledge from their friends and older sisters, and that sex education be provided by physicians, health personnel, and teachers.

\section{Conclusion:}

The majority of studied parents have positive attitudes towards sex-education to their children. Parental sex (female) and age of parents (category of 45 - 54 years for father, and $35-44$ years for mother), mother' education (university education), and urban residency are factors which influences parents' attitudes toward importance of sex education.

\section{Recommendations:}

1. Encouraging research and studies on sex education, and conducting analytical studies on the sources of sexual education

2. Conducting more research on trends towards sex education in a larger sample.
3. Arrange obligatory training program and workshops for parents of 10 years or more children on their sex education

\section{References}

- Adogu P \& Nwafulume O (2015): Knowledge, Attitude and Willingness to Teach Sexuality Education among Secondary School Teachers in Nnewi, Nigeria. BJESBS, 7(3): 184-193, 2015; Article no.BJESBS.2015.082 Aku Baku E, Agbemafle I, \& Adanu RM (2017): Effects of parents training on parents' knowledge and attitudes about adolescent sexuality in Accra Metropolis, Ghana. Reproductive Health 2017. 14:101

- Ariadni DK, YayiSuryo Prabandari Y, \& Sumarni DW (2017): Parents' Perception Having Children with Intellectual Disability Providing Sex Education: A Qualitative Study in Yogyakarta. Galore International Journal of Health Sciences and Research. Vol.2; Issue: 3; Sept. 2017.Website: www.gijhsr.com P-ISSN: 2456-9321

- Beech S \& Sayer L (2018): Analysis of sexual healthcare provided by school nurses. Primary Health Care Research \& Development, Volume 19 , Issue 3 , May 2018, pp. $288-300$.

- Bostani Khalesi Z, Simbar M, \& Azin S (2017): A qualitative study of sexual health education among Iranian engaged couples. Afri Health Sci. 2017; 17(2): 382-390.

- Breuner C \& Mattson G (2016): Sexuality Education for Children and Adolescents. Pediatrics August 2016, volume 138 / issue 2

- Campbell R. (2017): What is best practice in sex and relationship education? A synthesis of evidence, including stakeholders' views. British Medical Journal Open. 2017 Jul 2; 7(5): e014791. doi: 10.1136/bmjopen-2016-014791.

http://bmjopen.bmj.com/ content/bmjopen/7/5/e014791.full.pdf (Accessed 21 July 2017).

- Flores D \& Barroso J (2017): 21st century parentchild sex communication in the United States: A process review. The Journal of Sex Research 2017; 54 (4-5):532-548.

- Ghorbani M, Zamani-Alavijeh F, Shahry P, Zare K, \& Marashi T (2015): Understanding Childhood's Sexual Curiosity: An Introduction to Sexual Health Education and Health Promotion. Iran J Health Educ Health Promot 2015, 3(3): 198210

- Gurol, A., Polat, S., \& Oran, T (2014): Views of Mothers Having Children with Intellectual Disability Regarding Sexual Education: A Qualitative Study. Sexuality and Disability. 2014; 32: 123-133. 
- Haberland, N., \& Rogow, D. (2015): Sexuality education: Emerging trends in evidence \& practice. Journal of Adolescent Health, 56(1),S15-S21

- Hassan H (2013): A survey of father-son communication concerning sexual and reproductive health in Sharkiya, Egypt

- Hildie L., Daniel T., Shek, E., \& Esther Y. (2019): Development of Contextually-relevant Sexuality Education: Lessons from a Comprehensive Review of Adolescent Sexuality Education Across Cultures. Int J Environ Res Public Health. 16(4): 621. doi: 10.3390/ijerph16040621

- Jankovi S, Malatestini G \& Striehl H (2013): Parents' Attitudes on Sexual Education- What and When? Collegium Antropologicum 37(1):17-22. Available from: https://www.researchgate.net/publication/23693113 1 Parents' attitudes on sexual education What and when [accessed Feb 05 2021].

- Jo MJ, Lim KJ, \& Choi EJ (2013): Influencing factors of marital intimacy and sexual knowledge on parental efficacy of mothers with preschoolers on child sexual education. Journal of Korean Public Health Nursing 2018; 32(2):181193 https://doi.org/10.5932/JKPHN.2018.32.2.181.

- Katz, G., \& Ponce, E. (2008): Sexuality in Subjects with Intellectual Disability: An Educational Intervention Proposal for Parents and Counselors in Developing Countries. Salud Publica Mex, 50:S239-S254.

- Lee EM \& Kweon YR (2013): Effects of a maternal sexuality education program for mothers of preschoolers. Journal of Korean Academy of Nursing 2013;43 (3):370-378

- Lukolo LN \& Dyk A (2015): Parents' Participation in the Sexuality Education of Their Children in Rural Namibia: A Situational Analysis. Glob J Health Sci. 2015 Jan; 7(1): 35-45.

- Millner V, Mulekar M \& Turrens J (2015): Parents' Beliefs Regarding Sex Education for Their Children in Southern Alabama Public Schools. Sex Res Soc Policy vol.12, no 1

- Nghipondoka- Lukolo LN \& Charles KL (2016): Parents' Participation in the Sexuality Education of Their Children in Namibia: A Framework and an Educational Programme for Enhanced Action. Glob J Health Sci. 8(4): 172-187.

- Nyarko K, Adentwi KI, Asumeng M, \& Linda Dede Ahulu L (2014): Parental attitude towards sex education at the lower primary in Ghana. International Journal of Elementary Education 2014; 3(2):21-29 Published online April 10, 2014 (http://www.sciencepublishinggroup.com/j/ijeedu). doi: 10.11648/j.ijeedu.20140302.11

- Obiunu JJ (2014): The Influence of Sexuality Education on Inappropriate Sexual Behaviours among Secondary School Students. Advances in Research. 2(12): 869-878,

- Orgocka A (2010): Perceptions of communication and education about sexuality among Muslim immigrant girls in the US. Sex education2004; 4(3): [1screen]. Available from: http://www.informaworld.com/smpp/content $\sim \mathrm{db}=\mathrm{al}$ $\underline{1 \sim \text { content }=\mathrm{a} 713631339 \sim \mathrm{frm}=\mathrm{abslink}}$. Accessed on: October 12, 2010.

- Population Council. (2016): "Survey of young people in Egypt." Final Report. Cairo: Population Council.

- Roudi-Fahimi F (2011): Facts of Life: Youth Sexuality and Reproductive Health in the Middle East and North Africa (Washington, DC: Population Reference Bureau, 2011);

- Shetty P, Kowli SH, \& Patil V (2010): Attitude of mothers towards sex education of adolescent girls. Regional health forum WHO south-east Asian region; 3: [6pages]. Available from: http://www.searo.who.int/en/Section1243/Section13 10/Section1343/Section1344/Section1351/Section1 686 7197.htm. Accessed on: September 06, 2010.

- Shin H, Lee J, \& Min J (2019): Sexual Knowledge, Sexual Attitudes, and Perceptions and Actualities of Sex Education among Elementary School Parents. Child Health Nurs Res. 25(3):312323

- Tayo A \& Olawuyi B (2016): Parental Communication as a Tool Kit for Preventing Sexual Abuse among Adolescent Secondary School Students. Journal of Education and Practice. Vol.7, No.13, 2016

- UNICEF \&Ministry of Education (2016): Review of Comprehensive Sexuality Education in Thailand. Bangkok, UNICEF. http://hivhealthclearinghouse. unesco.org/sites/default/files/resources/ comprehensivesexualityeducationthailand_en.pdf

- Vashistha KC (2012): A Study of Attitude towards Sex-Education as Perceived by Parents \& Teachers s a m w a a d : e - journalis s n : $2277-749$ 0 2012: vol. 1 no. 2 page 64 of 124

- World Health Organization (2018): Regional Office for Europe, Sexuality education in Europe and Central Asia: state of the art and recent developments. An overview of 25 countries.

- Fentahun N, Assefa T, Alemseged F, \& Ambaw F (2012): Parents' Perception, Students' and Teachers' Attitude towards School Sex Education. Ethiop J Health Sci. 2012 Jul; 22(2): 99-106.

- Netshisaulu KG, Netshikweta ML \& Tshitangano TG (2015): Parental Attitudes towards Sex Education to Teenage Girls in Vhembe District of Limpopo Province. Journal of Human Ecology Vol. 51- Issue 1-2 
- Robinson K, Smith E \& Davies C (2017): Responsibilities, tensions and ways forward: parents' perspectives on children's sexuality education. Sex Education, 17:3, 333347, DOI: $10.1080 / 14681811.2017 .1301904$

- Kashik M (2012): Parents' attitudes towards teaching the concepts of sex education. In the basic education stage, a field study on a sample of fathers and mothers in Damascus and its countryside. Dam University Journal - Vol. 28, Issue 3-2 